\title{
Investigating Conceptual Foundations of Design Ability: An Analysis Through the Expressions of the Experiencing Mind
}

\author{
Ulusan, Ufuk \& Turan, Ahmet Zeki. \\ ${ }^{a}$ Mimar Sinan Fine Arts University, Turkey. uluufuk@yahoo.com. \\ ${ }^{\mathrm{b}}$ Mimar Sinan Fine Arts University, Turkey. ahmet.zeki.turan@msgsu.edu.tr.
}

\begin{abstract}
This paper aims to reveal conceptual foundations of design ability based on verbal expressions of students' insights. This goal is based on two propositions. The first one is about categorizing abilities in order to make them meaningful, while the second one is about the disadvantages of explaining the designer based on linear levels. So that, a group, which consisted of industrial design students who were newly graduated or in their last semester, was interviewed individually. The interviews were based on their experiences and the evolution of skills during four years of undergraduate education. Semi-structured interviews were used as the main data collection method, resulting over ten hours of recording which turned to be over one hundred pages of transcriptions. Later, the gathered data was analyzed using thematic analysis. Chunks of data were coded and codes were categorized under themes in a reductionist manner within several iterations. Three conceptual themes were generated and interpreted. Themes' reliability was ensured by using KALPHA in SPSS. Examples from four creative areas were given in order to broaden the field where the themes may be applied. As the final outcome, a model of fractal triangle simultaneously showing the findings is suggested. This model is claimed to indicate conceptual foundations which allow different states of design ability categories without being restricted to designer's expertise levels. So that, without depending on the specified designer level, different levels of ability categories become possible.
\end{abstract}

Keywords: design ability, conceptual foundations, thematic analysis.

\section{Introduction}

There are plenty of studies about design ability. One of the fundamental works about what the designers do is 'The nature and nurture of design ability' by Cross. In it, he explains the core features of design ability as "resolve ill-defined problems, adopt solution-focusing strategies, employ abductive/productive/appositional thinking, use non-verbal, graphic/spatial modelling media" (Cross, 1990, p.132). 
There is also a variety of studies about the evolution of the designer itself based on the things he/she does through this development process. As a primary study, Dorst discusses design expertise and defines several levels including 'naïve,' 'novice,' 'advanced beginner,' 'competent,' 'expert,' 'master' and 'visionary' (Dorst, 2011, 2008, 2003). These levels are detailed based on what the designers do and how they behave on each level.

The argument of this paper is based on two propositions. The first proposition is that; dozens of abilities can be listed about what the designer does, but it may not be meaningful unless they are finely categorized and the categories are interpreted. The second suggestion is that; distinct levels of expertise can be identified but that does not necessarily mean that one must be restricted to a level while he/she can be 'novice' on some ability and 'master' on the other at the same time.

Based on these propositions, conceptual foundations of design ability are investigated. Design abilities are categorized under three main themes within several iterations, elaborating about where they belong and what they mean. Also because this categorization is not based on specified designer levels, but on themes of abilities instead, the designer is not restricted to any level through his/her development.

\section{Methodology}

\subsection{Sampling}

This paper studies design ability based on verbal expressions of students' insights. Being a qualitative study, it focuses on a purposive and relatively small sample. The sample consists of fourteen participants who are newly graduated or in their last semester. These participants are selected in accordance with some specific criteria such as having a clear insight of their development as a designer, being able to reflect his/her experiences, having strong linguistic skills and being keen on an interview. They are chosen among two fundamental universities providing industrial design education in Turkey having two different systems of student acceptance. The selected universities are İstanbul Technical University and Mimar Sinan Fine Arts University.

\subsection{Data Gathering}

Semi-structured questions are asked about the participants' evolution of skills and experiences during their undergraduate education. The questions are focused on differences of abilities between the time when they first came to school and reached the end of their undergraduate education. The interviews are carried out individually and seen as informal chats rather than formal meetings by both the participants and the interviewer. The shortest interview took about half an hour and the longest one about an hour. The gathered data consists of over ten hours of audio recording which turns into over a hundred pages of verbal transcriptions.

\subsection{Data Analyzing}

The main method used for analyzing the data is thematic analysis which is also called thematic synthesis. Braun and Clarke describe it as a method for "identifying, analyzing and reporting patterns (themes) within data" (Braun, Clarke, 2006, p.6); while Attride-Stirling identifies six steps to create thematic networks: "Code material, identify themes, construct thematic networks, describe and explore thematic networks, interpret patterns" (Attride-Stirling, 2001, p.391). Thomas and Harden identify three stages in the process: "The free line-by-line coding of the findings of primary studies, the organization of these 'free codes' into related areas to construct 'descriptive themes' and the development of 'analytical' themes" (Thomas, Harden, 2008, p.7); while Robson describes six steps: "Familiarizing yourself with the 
data, generating initial codes, identifying themes, constructing thematic networks, integration and interpretation" (Robson, 2011, p.476).

Whatever the description and the quantity of the process' stages may be, the main idea of this method is based on coding the data and categorizing the codes to create inclusive themes to gain a holistic view on the subject.

In this context, any segment of the data which refers to design ability - whether it is a section, paragraph, sentence, phrase or a word - is labeled with a code. The codes are grouped under subsets, the subsets under sets, and sets under themes. In the scope of this study, there emerged 320 codes, 35 subsets, 10 sets and 3 themes.

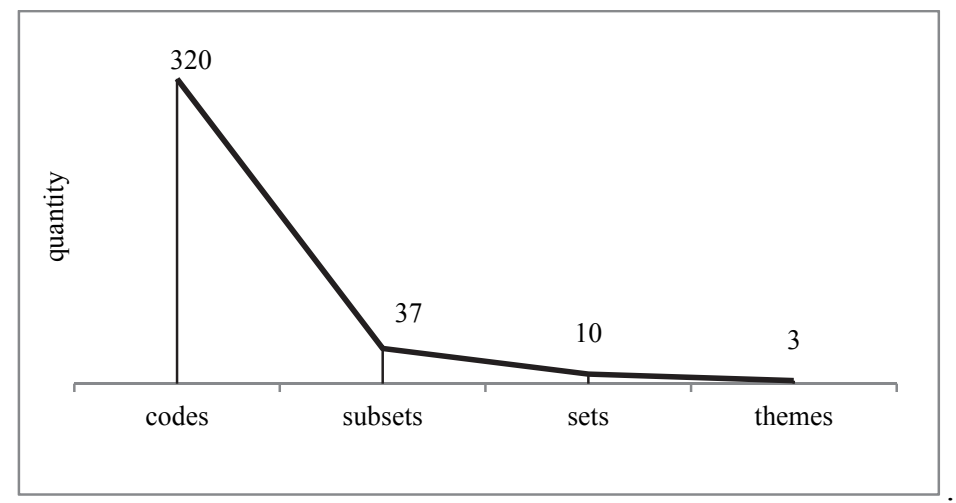

Fig. 1 Analysis Process Quantities.

The categorizing process is mainly based on establishing similarities of meanings and logical relations between the elements. Once these relations and similarities are established, they are categorized under one level higher. The categories are determined according to their cores rather than boundaries. This approach is mainly based on an example Rosch gives in which she mentions about "two neighbors" (Rosch, 1978, p.11).

She says that these two neighbors "know on whose property they are standing without exact demarcation of the boundary line" in her study about principles of categorization (Rosch, 1978, p.11). Based on this perspective, it can be inferred that the cores of the categories in this study are static, defined, definite and separate from each other while the boundaries are nested, cloudy, vague and intermingled. While an infinite number of relations exist between the categories, they still can be distinguished looking on their distinct characteristics of their cores. 


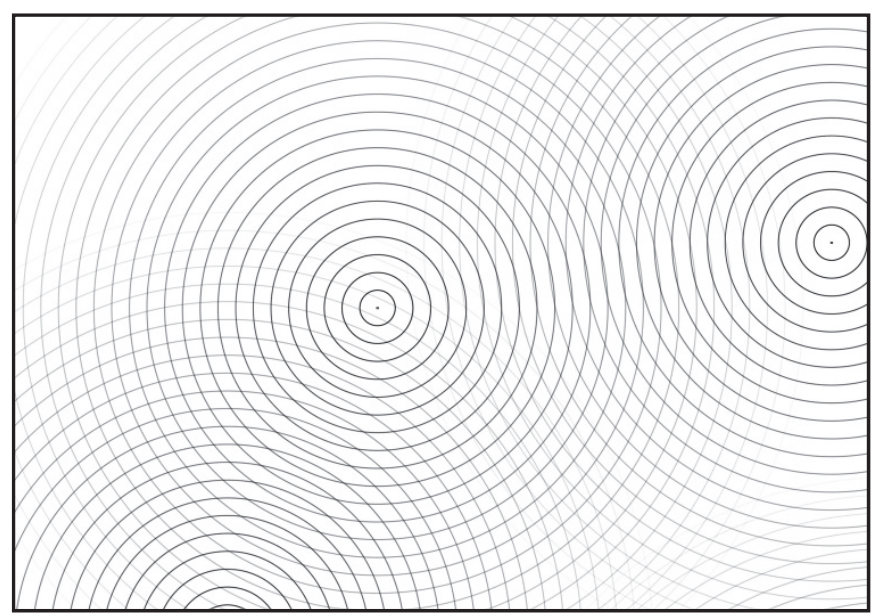

Fig. 2 Categories determined by their cores rather than boundaries.

\subsection{Reliability}

As the final outcome of the categorization process, themes are tested for reliability using Krippendorff's Alpha (Kalpha). Kalpha is a macro for SPSS. Hayes and Krippendorff refer to it as "general in that it can be used regardless of the number of observers, levels of measurement, sample sizes, and presence or absence of the missing data" (Hayes, Krippendorff, 2007, p.77).

Four independent observers are given the segmented transcript of the interviews to code them individually. They are also provided with a brief description of the themes and are asked about which theme each of the 320 segments could fit into. The observers are informed that they can leave any of the segments blank in case they think that it does not fit into any of the themes, have a hesitation, or disagree with the themes. The transcriptions are divided into half and given to the observers in two sessions to reduce the risk of distraction because of the large quantity of data. As a result the Kalpha value is found to be '.6617'

The Kalpha value indicates the level of agreement between the independent observers. Swert suggests that "Kalpha=.80 is often brought forward as the norm for a good reliability test, with a minimum of .67 or even .60 (when it is that low, you might give some specific information why this is low and why you still choose to accept this variable in your analysis)"(Swert, 2012, p.5).

The reason why this value is accepted is based on three arguments. The first one is about a bad coder noticed amongst the other three. Swert says "bad coders could give you a misleading Kalpha" (Swert, 2012 , p.5). So when that coder is dropped from the test, the Kalpha value significantly raises to '.7352' as the agreement between rest of the coders. The second reason is about the large quantity of the segments. 320 pieces are thought to be an extreme number for coding compared to an example of 30 that Swert gives (Swert, 2012). The third point is the abstract property of the themes compared to some concrete criteria like presence of a physical entity. 


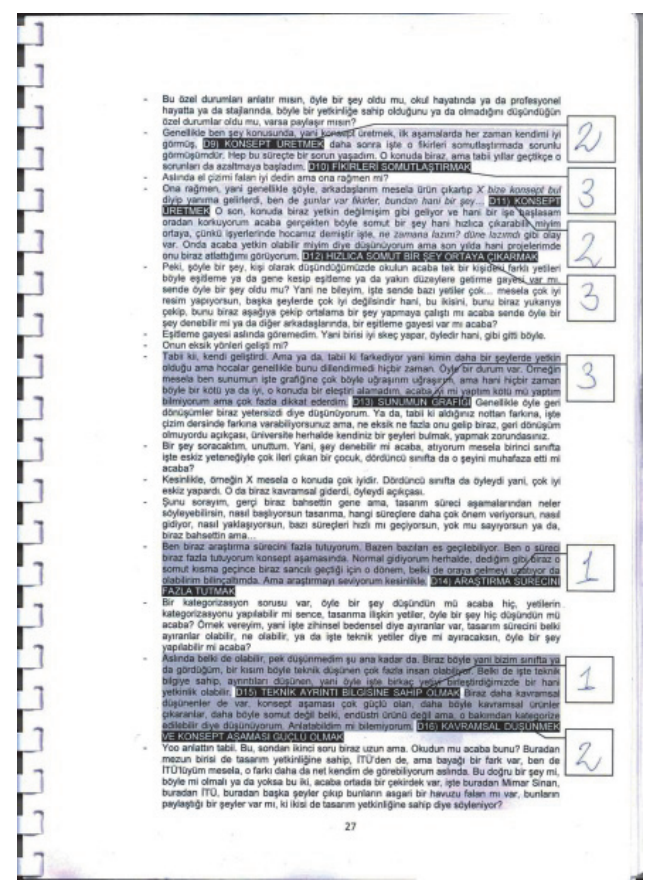

Fig. 3 Example of one page from the transcriptions in Turkish after the Kalpha reliability test. The unpainted parts refer to sections which are not coded while the grey highlighted segments refer to coded ones. The phrases colored black are the codes. The numbers on the right hand side represent the observer's judgements of placing segments and codes together into themes. For example 'I' is the number representing 'theme 1 ' and so on.

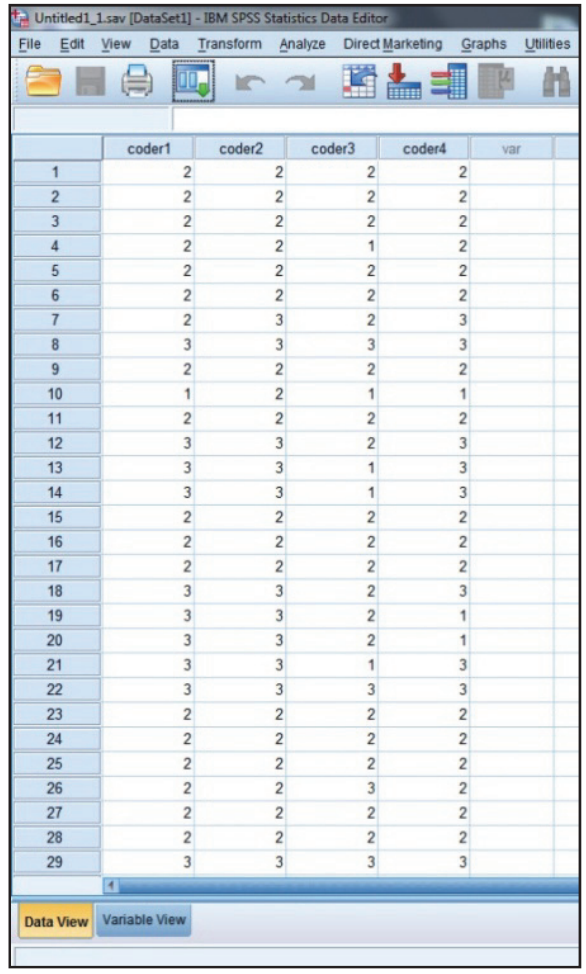

Fig. 4 A part of the choices of four coders in SPSS. The column on the left hand side shows the list of the coded segments which goes down to 320, the upper row shows the coders, the numbers in the cells (1,2 or 3) show the coders' choices of the themes. 


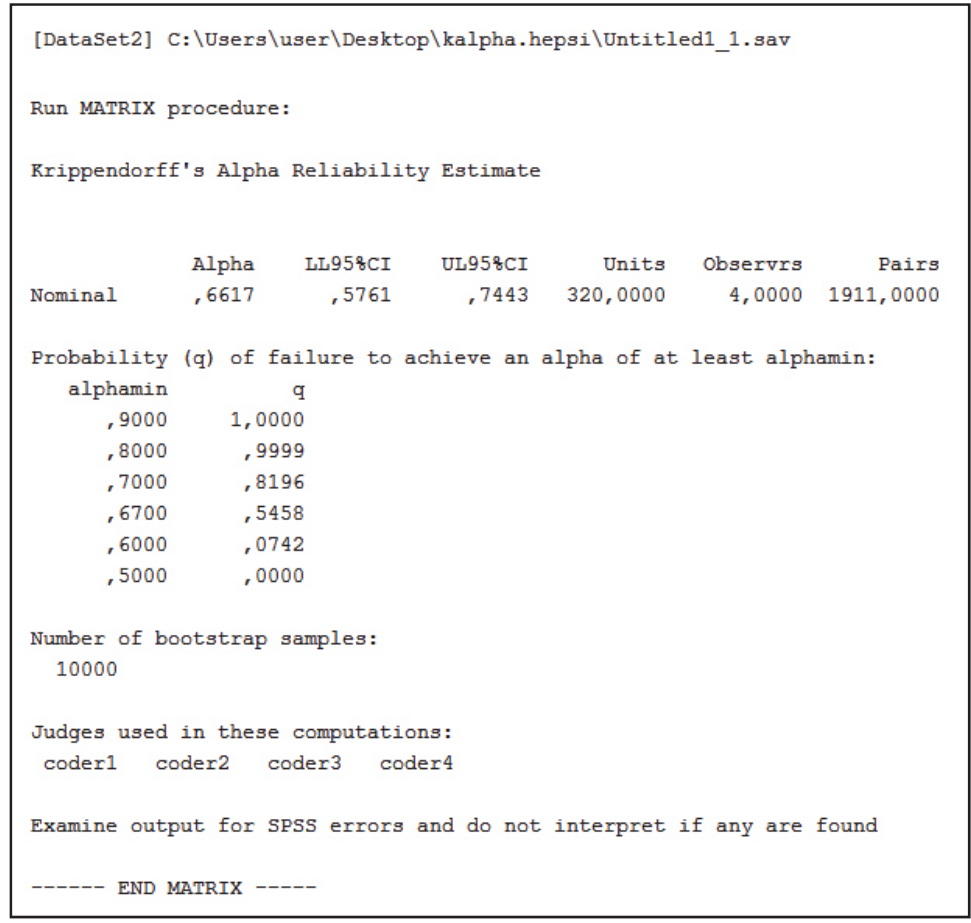

Fig. 5 The calculated Kalpha value of '.6617'.

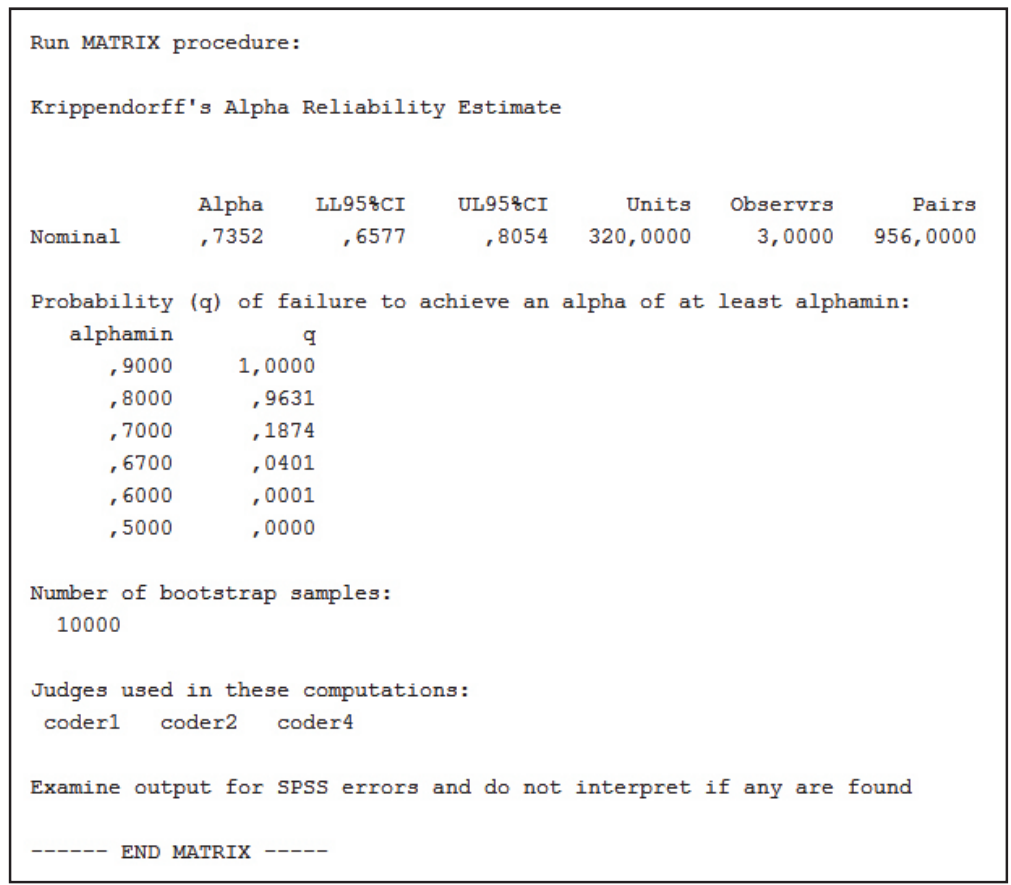

Fig. 6 The calculated Kalpha value of ' 7352 ' after the 'bad coder' is dropped from the test. 


\section{Process and Findings}

\subsection{Codes}

Following the procedures 320 codes are generated from the transcriptions. The codes are not listed here because of the large quantity.

\subsection{Subsets}

320 codes are distributed to 37 subsets based on similarities of meanings and logical relations. The subsets are as follows:

- $\quad$ Description (20 codes)

- $\quad$ Exploration (19 codes)

- $\quad$ Thinking (19 codes)

- $\quad$ Shaping (17 codes)

- $\quad$ Presentation (17 codes)

- $\quad$ Concept (14 codes)

- $\quad$ Process (14 codes)

- $\quad$ Analysis (12 codes)

- $\quad$ User (12 codes)

- $\quad$ Comprehension (10 codes)

- $\quad$ Idea (10 codes)

- $\quad$ Building (10 codes)

- $\quad$ Questioning (10 codes)

- $\quad$ Technical Data (10 codes)

- $\quad$ Material ( 9 codes)

- $\quad$ Method (9 codes)

- $\quad$ Scenario (8 codes)

- $\quad$ Semantics (7 codes)

- $\quad$ Production (7 codes)

- $\quad$ Management (7 codes)

- $\quad$ Knowing The Past (6 codes)

- $\quad$ Expression (6 codes)

- $\quad$ Mechanics (6 codes)

- $\quad$ Structure (6 codes) 
- $\quad$ Technical Details (6 codes)

- $\quad$ Graphics (5 codes)

- $\quad$ Awareness (5 codes)

- $\quad$ Learning $(5$ codes $)$

- $\quad$ Solving (4 codes)

- $\quad$ Dissection (4 codes)

- $\quad$ Philosophy (4 codes)

- $\quad$ Keeping up to Date (4 codes)

- $\quad$ User Emotions (4 codes)

- $\quad$ Market (4 codes)

- 3D Comprehension(4 codes)

- $\quad$ Data Gathering (3 codes)

- $\quad$ Intuition (3 codes)

\subsection{Sets}

The reduction steps from the subsets to the sets and from the sets to the themes require establishing deeper relations and eventually a more thorough categorization. This way, in addition to the researcher's mind and word processor software, the elements are studied with actual slips of paper. As a result, 37 subsets are distributed to 10 sets based on similarities of meanings and logical relations. 


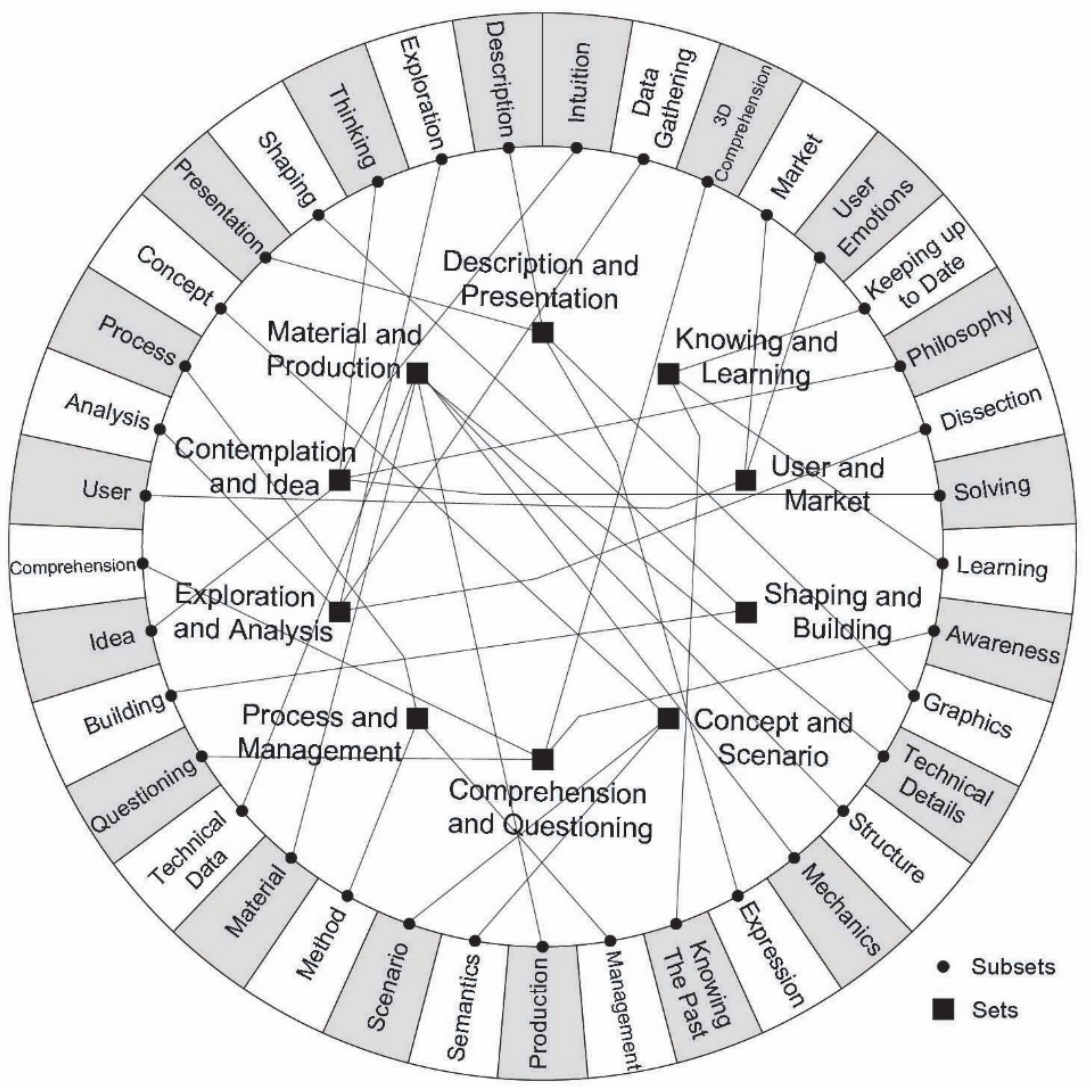

Fig. 737 subsets distributed to 10 sets.

The sets generated are as follows:

- 'Description and Presentation' set; refers to transmission of a mental entity towards the physical world. It contains 'Description,' 'Presentation,' 'Expression' and 'Graphics' subsets.

- 'Material and Production' set; refers to the restrictions and potentials of the production process and the data of how the materialized entity may be operational along with the physical terms of the outer world. It contains 'Technical Data,' 'Material,' 'Production,' 'Mechanics,' 'Structure' and 'Technical Details' subsets.

- 'Contemplation and Idea' set; refers to all kinds of abstract intellectual and emotional activities. It contains 'Thinking,' 'Idea,' 'Solving,' 'Philosophy' and 'Intuition' subsets.

- 'Exploration and Analysis' set refers to activities of searching, finding and analyzing something that has not been known and discovered till that time. It contains 'Exploration,' 'Analysis,' 'Dissection' and 'Data Gathering' subsets.

- 'Process and Management' set refers to activities of governing, managing, leading, ruling and directing a process in a period of time. It contains 'Process,' 'Method' and 'Management' subsets. 
- 'Comprehension and Questioning' set refers to a state of comprehension reached as a result of a questioning, criticizing and realizing process, including comprehension of 3 dimensions. It contains 'Comprehension,' 'Questioning,' 'Awareness' and '3D Comprehension' subsets.

- 'Concept and Scenario' set refers to activities of adding meanings to an entity, associating it with a conceptual level and integrating it within a fictional context. It contains 'Concept,' 'Scenario' and 'Semantics' subsets.

- 'Shaping and Building' set refers to the act of revealing any kind of abstract phenomenon by forming and also the shape itself at the end of the process. It includes 'Shaping' and 'Building' subsets.

- 'User and Market' set refers to users, usage attributions and the market. It includes 'User,' 'User Emotions' and 'Market' subsets.

- 'Knowing and Learning' set refers to a general knowing activity upon acting the present and a general learning activity towards looking at the past. It includes 'Knowing the Past,' 'Learning' and 'Keeping up to Date' subsets.

\subsection{Themes}

Finally 10 sets are distributed to 3 themes based on similarities of meanings and logical relations. The names of the themes; 'Exposure', 'Essence', 'Intervention' are determined according to their core meanings.

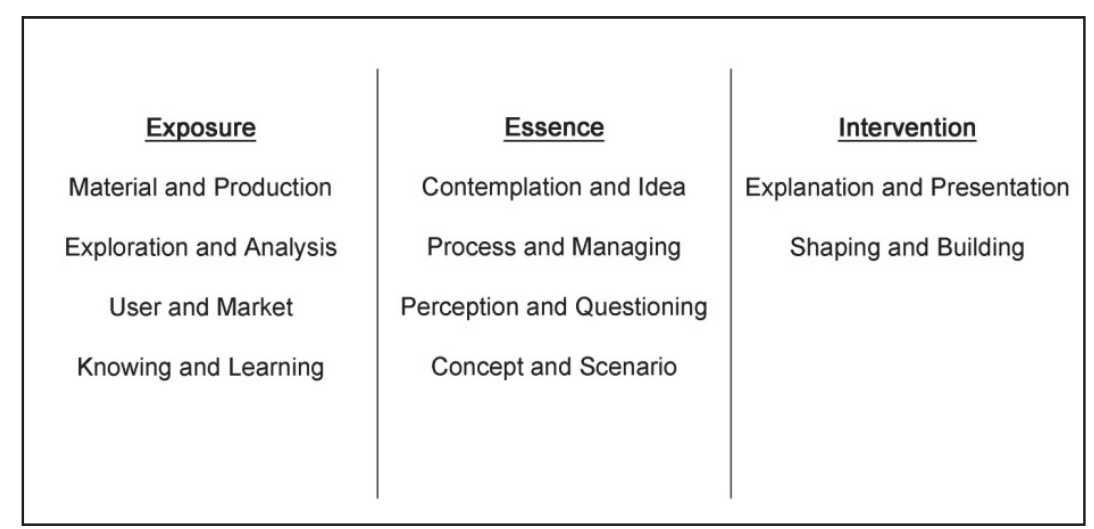

Fig. 810 sets are distributed to 3 themes

'Exposure' theme includes 'Material and Production', 'Exploration and Analysis', 'User and Market' and 'Knowing and Learning' sets. It refers to any kind of data its sets offer to which the designer gets exposed during the design process. This state of being vulnerable to any kind of data is the main attribution of this set. This is the passivity and inaction of the designer compared to the 'Intervention' theme. This theme stands for the relation between the designer and the existing terms of the outer world without any proposal or intervention of the designer. However, passivity of the designer here does not mean attaining the information without any effort. It refers to actions like analyzing, describing, explaining and using, by which the designer has no ambition to change the existing terms. 'Exposure' set, whether doing some technological study for an ongoing research for an advanced robot or observing the daily routine of a target group, is predominantly a mental transmission from the outer world into the brain through the senses of the designer. It involves descriptive claims for the 'past' by examining the 'world'. 
'Essence' theme includes 'Contemplation and Idea', 'Process and Managing', 'Perception and Questioning' and 'Concept and Scenario' sets. The word 'essence', beyond indicating a physical part of the human body like brain, points to a center point which manages the 'Exposure' and 'Intervention' themes. 'Essence' theme transforms into 'Exposure' theme by means of being exposed to the outer world and transforms into 'Intervention' theme by means of intervening it. What gives this theme its 'essence' attribution is the fact that while the other two themes can be simulated, this one cannot be. 'Exposure' theme can be simulated by tape recorders, marketing departments, cameras, eye and face tracking devices, research departments etc. while 'Intervention' theme can be imitated by $3 \mathrm{~d}$ software, $3 \mathrm{~d}$ printers, model makers etc. 'Essence' theme however, indicates abilities that have no equivalence, hence cannot be substituted or replaced. It synthesizes descriptive and normative claims for 'now' through the act of 'designing'.

'Intervention' theme includes 'Explanation and Presentation' and 'Shaping and Building' sets. It refers to the existing terms of the outer world which the designer wishes to change through a proposal through its sets. The state of proposing is the main attribution of this set. This is the activeness of the designer compared to the 'Exposure' set. This effectiveness and action state describes the relation between the designer and the existing terms of the outer world which is subject to change through proposals and interventions of the designer. It refers to active actions such as intervening, changing, effecting and proposing by which the designer has an ambition to change the existing terms. 'Intervention' set, whether construction of a skyscraper through many years of designing and building or a sketch of a water glass on some napkin, is predominantly a physical transmission from the brain to the outer world through the body of the designer. It involves normative claims in order to project what will happen in the 'future' through designing 'products'.

\subsection{Chart of Conceptual Foundations}

In this section of the paper, themes are discussed more broadly, used in a chart and applied to creative human activities as well as design. Four cases from graphic design, music, painting and literature are given as examples. The aim of giving such examples is to make a connection between designing products, visuals, songs, art pieces and novels, so that foundations of design ability may broadly be applied to other areas.

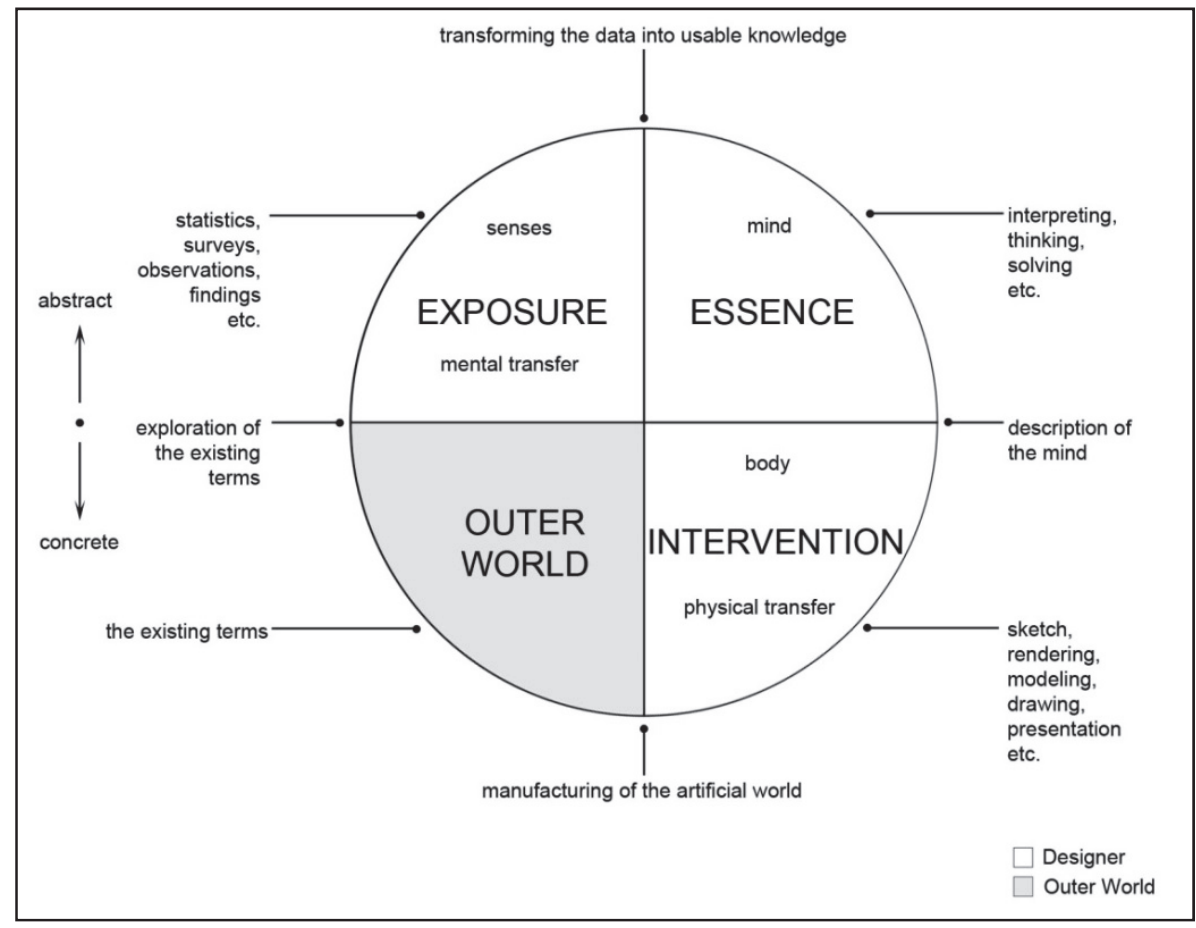

Fig. 9 Relations between the designer and the outer world shown in the chart 
The first example is an aphorism of an American graphic designer, Paula Scher:

"It took me a few seconds to draw it, but took me 34 years to learn how to draw it in a few seconds" (Airey, 2010, p.81).

Here it can be observed that Scher mentions but not underscores her drawing as an output. Instead, she emphasizes her life experiences which give rise to that drawing. In this sense she stresses 34 years which represent the 'Exposure' theme, rather than a few seconds which represent the 'Intervention' theme.

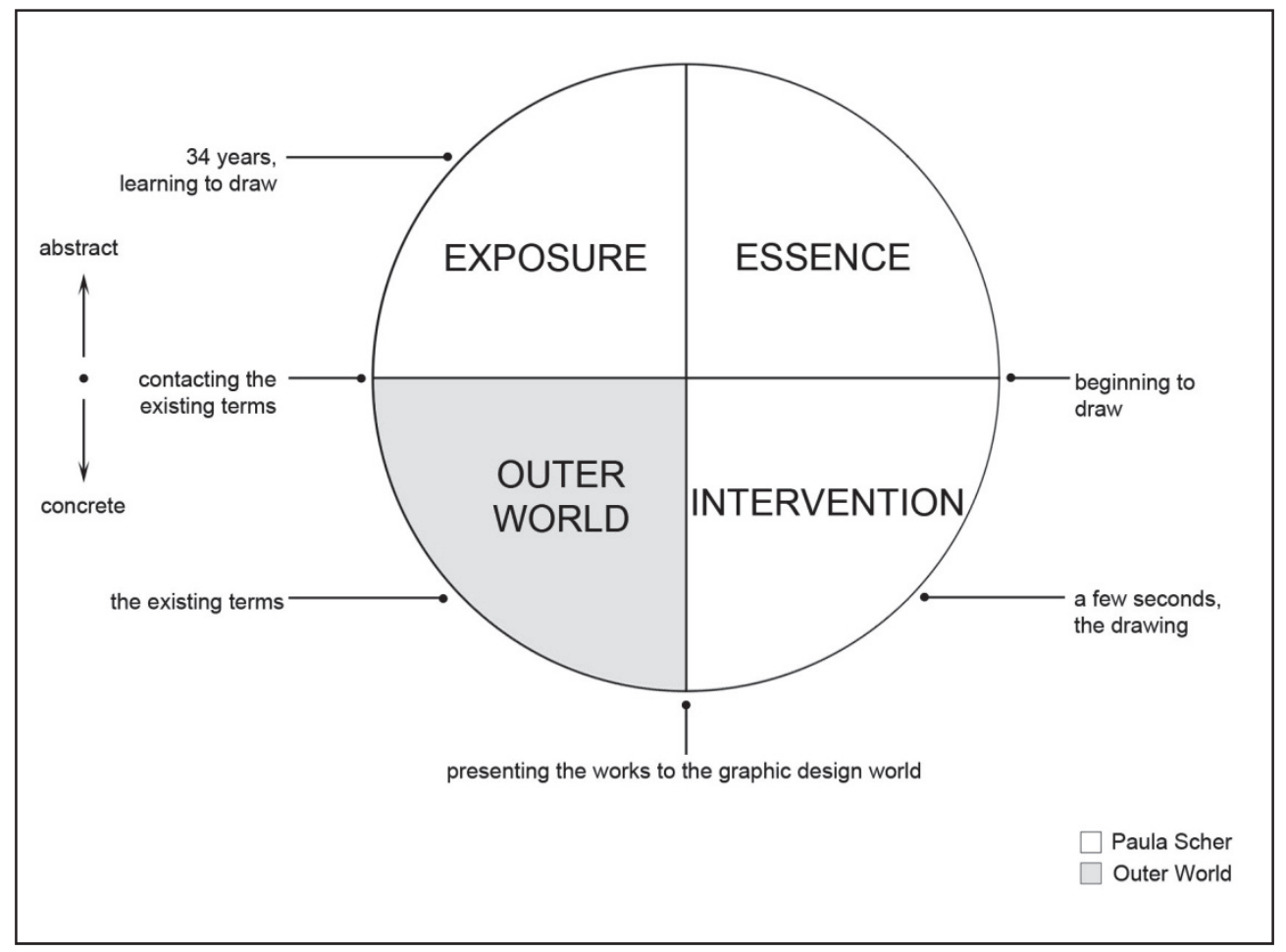

Fig. 10 Creation process of a graphical drawing shown in the chart.

The second example is about Ümit Besen, a Turkish singer, composer and song writer who discusses creation process of one of his famous songs, 'Nikah Masası' meaning 'wedding table' in English. He says:

"I wrote that song without knowing what it would be like. I wrote my feelings. I woke up from a dream and it just took me 20 minutes. I wonder there would be a wedding at that time! (...) The woman I was in love with would marry someone else according to the scenario of the first movie I acted in. That scenario overlapped with what I was experiencing at that time. That's the reason I wrote it. (...) I do not write songs when I am happy. I necessarily have to have the experience of yearning and separation. Or I feed myself with my friends' worries" (Aldinç, 2013).

In the background of this statement and beyond the time period of 20 minutes in which musical notes, melodies, chords or lyrics come physically into being as writings or sound waves; there are emotional experiences and a dream which the musician mentions implicitly on the creation of the song. If these elements are placed in the chart, it can be observed that the musician transforms data from outer world into experiences, yearnings and separations and transfers them into his brain, processes them in his mind 
consciously - or unconsciously like the dream he had - and turns them into a language suitable for the physical terms of the outer world in a time period of 20 minutes.

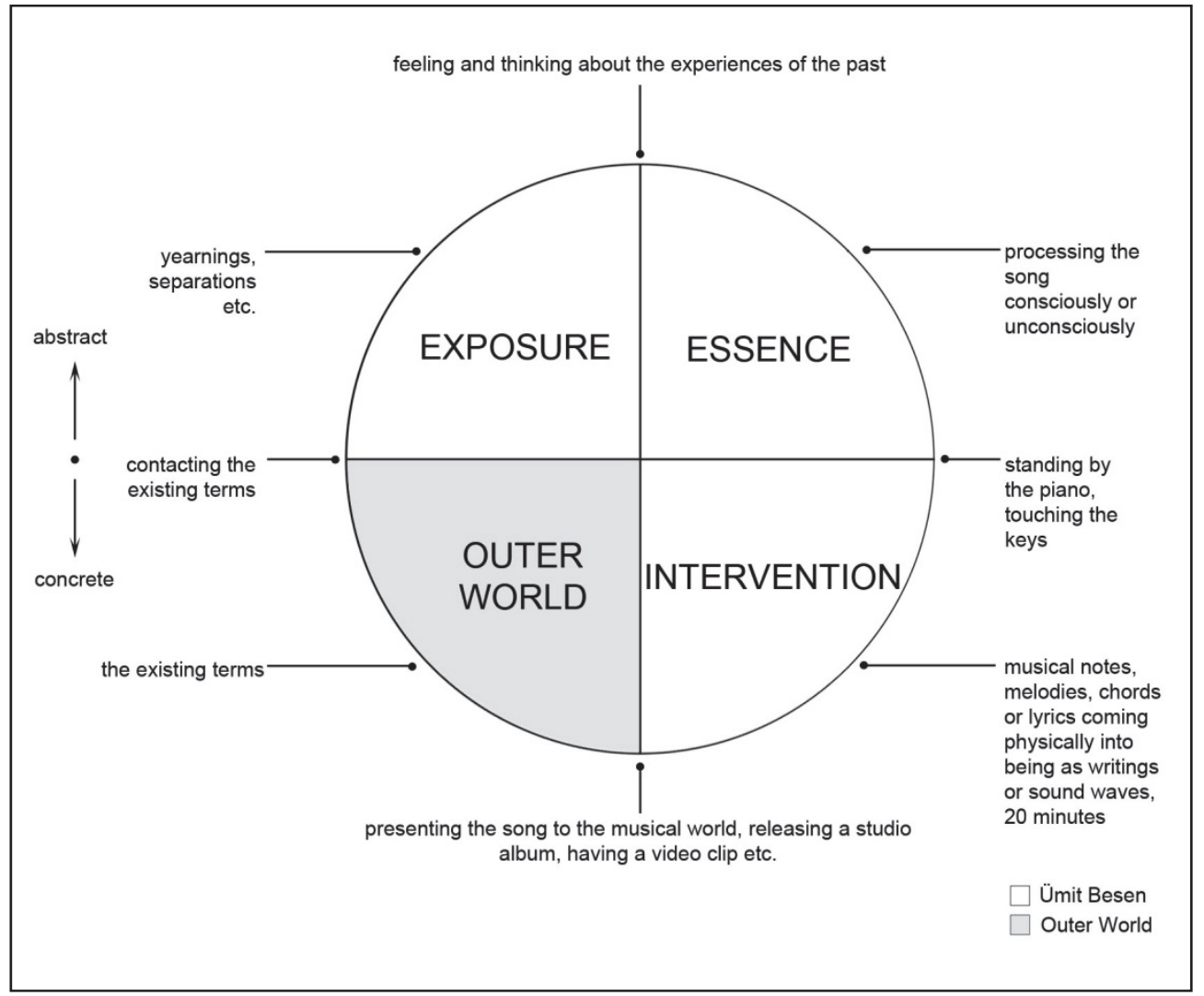

Fig. 11 Creation process of 'Nikah Masası' shown in the chart.

The third example consists of a famous anecdote about painting:

"In occupied Paris, a Gestapo officer who had barged his way into Picasso's apartment pointed at a photo of the mural, Guernica, asking: "Did you do that?" "No," Picasso replied, "you did", his wit fizzing with the anger that animates the piece" (In praise of ... Guernica, http://tinyurl.com/naatqx7).

Here it can be seen that Picasso emphasizes the background events that have effects on the context of the mural rather than the physical creation of it. In this sense it can be inferred that Picasso stresses the 'Exposure' theme. The bombing of Guernica, the impact it made and the impression it created on people, together, indicate the 'Exposure' theme while the physical entity of the mural, in other words the sum of the paint stains on the wall refer to the 'Intervention' theme. So that it can be said that the officer focuses on 'Intervention' theme while Picasso sticks on the 'Exposure' theme. 


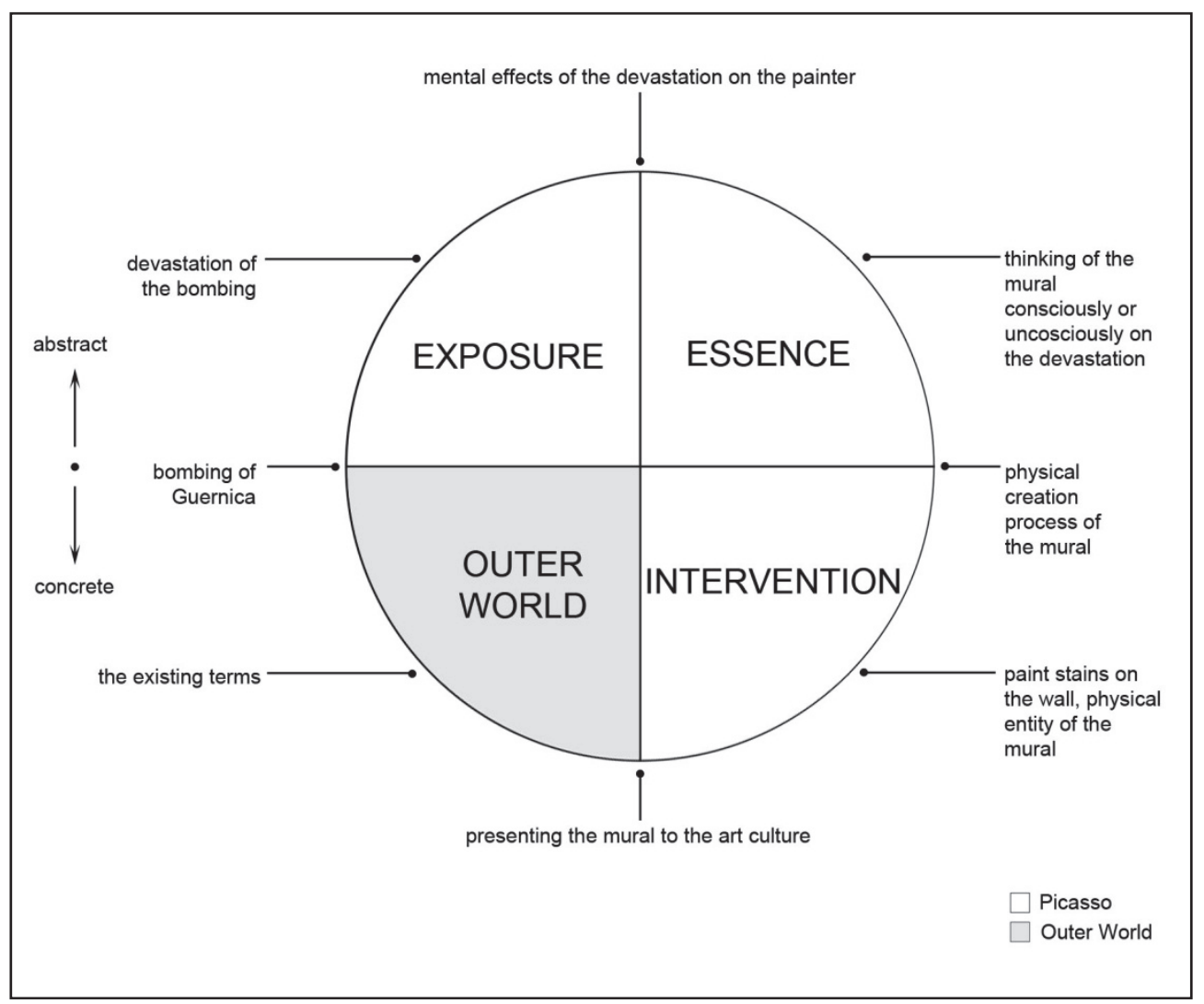

Fig. 12 Creation process of the 'Guernica' shown in the chart.

The fourth and last example consists of an aphorism on the field of literature narrated by Donaldson:

"Fitzgerald had been struggling to complete This Side of Paradise for two years - longer, if one considers how much of the book is borrowed from his undergraduate writing at Princeton - and it had gone through two substantial revisions before Scribners accepted it. But to the booksellers, Fitzgerald acknowledged none of these difficulties: "to write it ... took three months; to conceive it, three minutes; to collect all the data in it, all my life"'(Donaldson, 2001, p.164). 


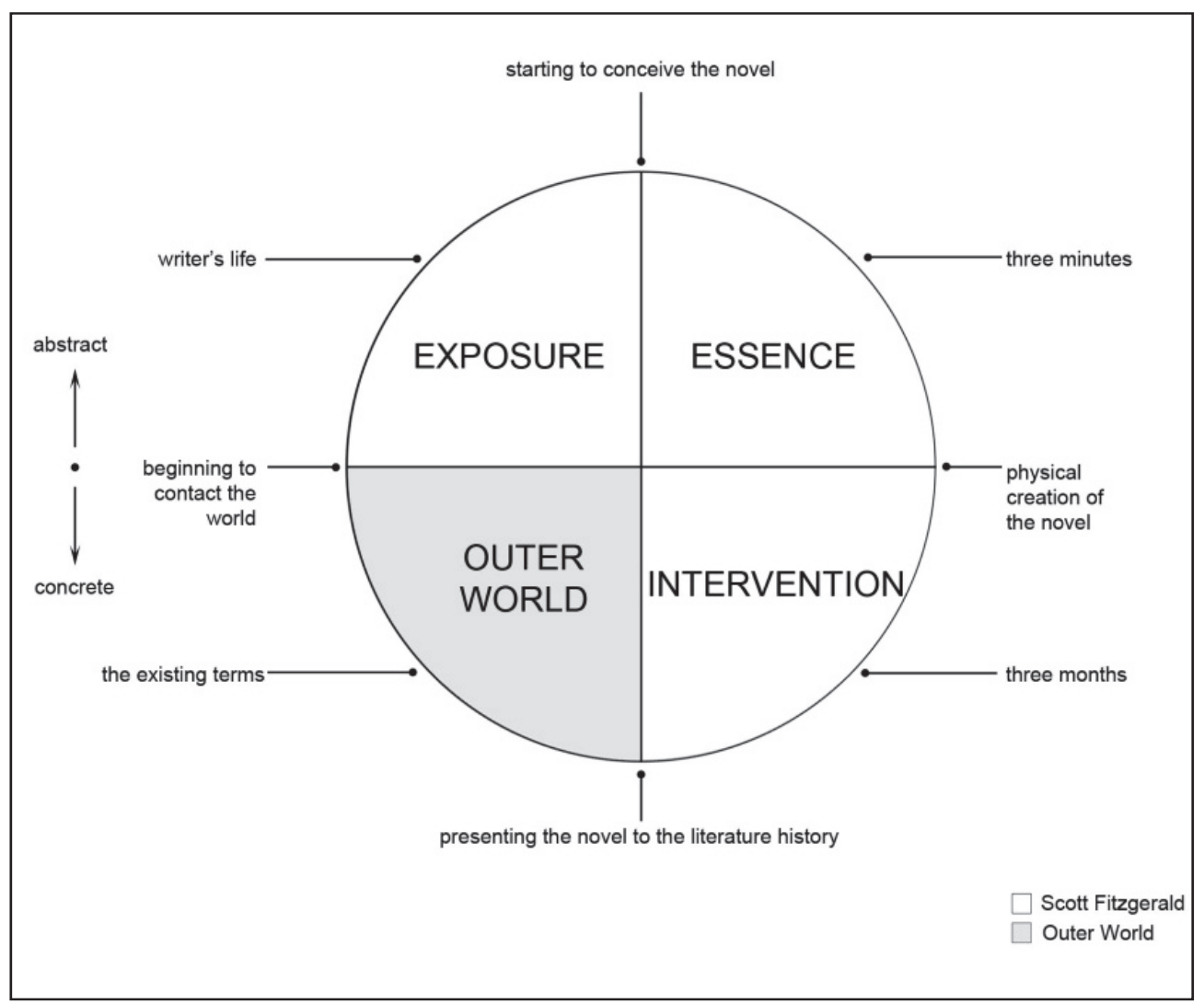

Fig. 13 Creation process of 'This Side of Paradise' shown in the chart.

Here it can be seen that Fitzgerald emphasizes his life experiences that has the largest effects on the creation of 'This Side of Paradise' rather than conceiving and writing processes of the novel. In this sense he stresses the 'Exposure' theme. The writer's life refers to the 'Exposure' theme; three months that represent the physical creation of the novel refer to the 'Intervention' theme and three minutes that represent the creation of the novel in his mind refer to the 'Essence' theme.

\section{Model}

The final outcome of this paper is a model used in order to show the findings of the process simultaneously. The findings can be interchanged, which means one element can be used instead of another one following its course in the model. To provide such mobility, a fractal triangle is suggested. One track goes 'exposure - senses - descriptive claim - past - world', one goes 'essence - mind descriptive and normative claim - now - design' and finally one goes 'intervention - body - normative claim - future - product'. 


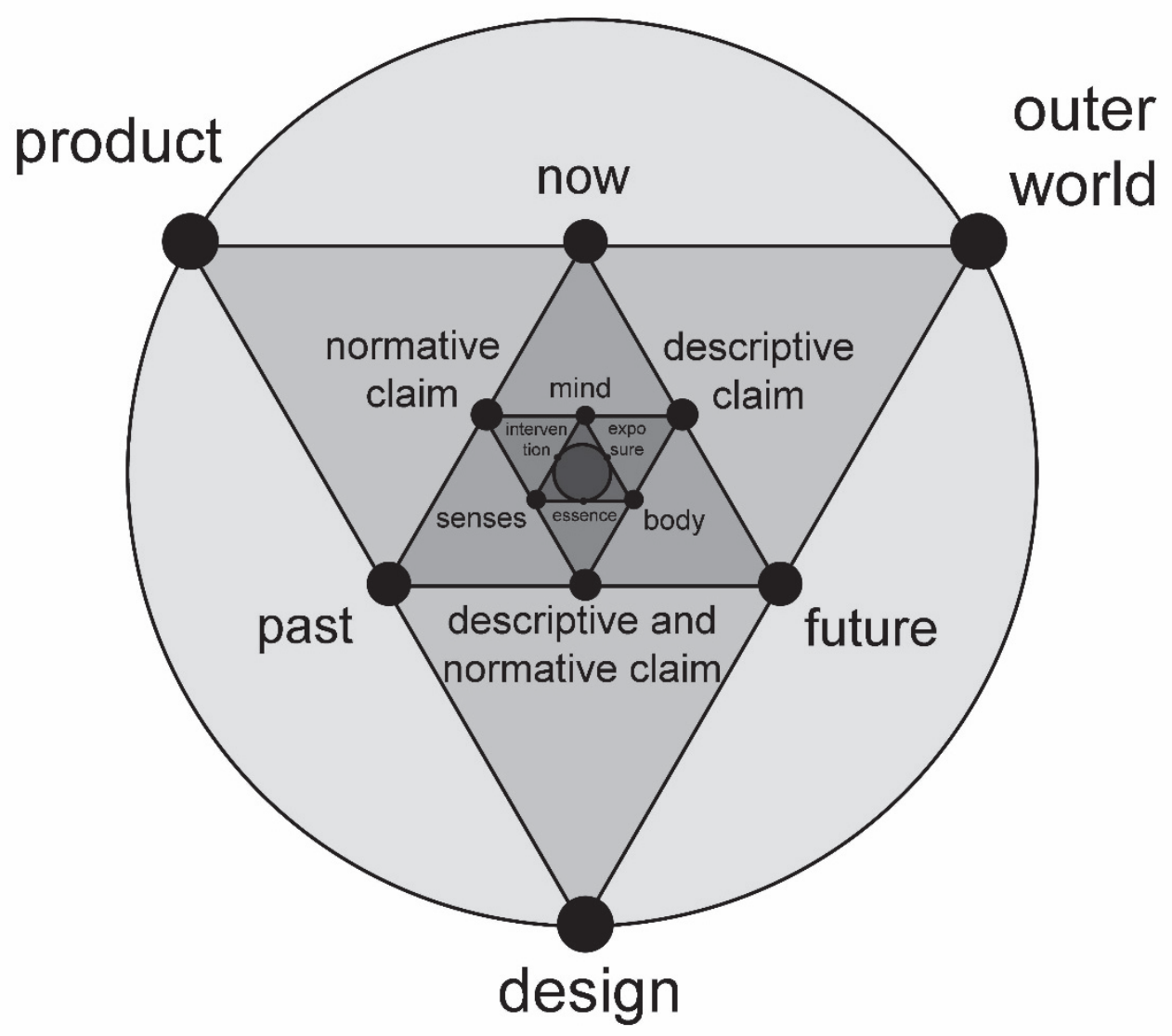

Fig. 14 A model of fractal triangles showing the findings of the paper.

\section{References}

AIREY, D. (2010). Logo Design Love: A guide to Creating Iconic Brand Identities. Berkeley, CA: New Riders.

ALDİNÇ, B. (2013). Arabaya biniyorsam en iyisi olmalı. Interview with Ümit Besen. Sabah. $<$ http://tinyurl.com/qxj6m9n> (Accessed 13 November, 2014).

ATTRIDE-STIRLING, J. (2001). "Thematic networks: an analytic tool for qualitative research" in Qualitative Research, vol 1(3), pp.385-405.

BRAUN, V., CLARKE, V. (2006). "Using thematic analysis in psychology" in Qualitative Research in Psychology, 3(2), pp.77-101.

CROSS, N. (1990). "The nature and nurture of design ability", Design Studies, 11(3), pp.127-140.

DE SWERT, K. (2012). Calculating inter-coder reliability in media content analysis using Krippendorff's Alpha, $<$ http://tinyurl.com/nmeudes>, (Accessed 21 September, 2014).

DONALDSON, S. (2001). "Fitzgerald's nonfiction", in Prigozy, R. (ed.). The Cambridge Companion To F. Scott Fitzgerald. UK: Cambridge University Press.

DORST, C., H. (2003). "The problem of design problems" in Edmonds, E. and Cross, N. (eds.), Expertise in Design, Design Thinking Research Symposium 6, Sydney, Australia: Creativity and Cognition Studios Press.

DORST, C., H. (2008). "Design research: a revolution-waiting-to-happen”, Design Studies, 29(1), pp.4-11.

DORST, C., H. (2011). “The core of 'design thinking' and its application”, Design Studies, 32(6), pp.521-532.

HAYES, A., F., KRIPPENDORFF, K. (2007). "Answering the call for a standard reliability measure for coding data", Communication Methods and Measures, 1(1), pp.77-89. 
In praise of ... Guernica, The Guardian editorial, <http://tinyurl.com/naatqx7>, (Accessed 24 September, 2014).

ROBSON, C. (2011). Real World Research (3rd edition), Wiley.

ROSCH, E. (1978). "Principles of categorization", in Rosch, E. and Lloyd, B., B. (eds.). Cognition and Categorization. Hillsdale, NJ: Erlbaumn. Reprinted in: Margolis, E. and Laurence, S. (eds.). (1999) Concepts: Core Readings, Cambridge: MIT Press.

THOMAS, J., HARDEN, A. (2008). Methods for the thematic synthesis of qualitative research in systematic reviews, BMC Medical Research Methodology, 8(45). 